\title{
Strategic Orientation and Human Resources Management in Public Sector Organizations in the Society 5.0 Era
}

\author{
Maria Elizabeth Lanny Kusuma Widjaja $\mathrm{a}^{*}$
}

\author{
${ }^{1}$ University of Surabaya, Surabaya, Indonesia \\ *Corresponding author. Email: lanny.kusumawidjaja@staff.ubaya.ac.id
}

\begin{abstract}
Strategic orientation is a principle that guides, directs, and influences organizational activities that produce behavior to ensure organizational survival, performance, and innovation. Public sector organizations in the society 5.0 era have the potential to face various changes, environmental uncertainties, and different tasks. Such conditions require a strategic emphasis that combines the Human Resource Management orientation and practices. It is recommended that public sector organizations in the society 5.0 era possess an analytical framework specific to their needs. The framework is developed from organizational orientations, practices, and innovations to assist public sector organizations' leaders in identifying the organization's strategic orientation and practices.
\end{abstract}

Keywords: Strategic Orientation, Human Resource Management, Change, Innovation.

\section{INTRODUCTION}

In public sector organizations, the demand for services increases but is not always accompanied by an increase in funding sources. Public sector organizations are increasingly adopting non-profit sector strategies and practices to increase efficiency, effectiveness, and performance. Public sector organizations are faced with scarcity of resources and pressure to be innovative, retaining a vastly bureaucratic orientation, and paying attention to the internal distribution of power. In the society 5.0 era, technological advancement forces change in society and organizational culture. Organizations that successfully handle various transformational changes can continue to evolve and adapt along with technological changes. (Agolla et al., 2017). Innovation is a big challenge for the society because it has a relationship with the tasks and roles played by the public sector in terms of technical, social, and economic transitions. However, innovation and public organizations seem to be on two opposite sides because the innovation attributes are often not shared by public sector organizations. (Demircioglu, 2017). Innovation accommodates ideas of technology and modernization; while on the other hand, public sector organizations are even seen as something that is left behind, full of bureaucratic and conservative structures. (Agolla et al., 2017). It seems that a culture like this has become a habit that is tolerated to be implemented by public sector organizations. However, in the society 5.0 era, this culture should be reduced and not be implemented. Innovation support lies in the strengths obtained from internal and external of the organization. Moreover, the public sector innovation drivers are indeed planned and made according to the community needs to be compiled based on the available budget, organizational strategy, availability of resources, and effective leader- 
ship at all levels of the organization (Agolla et al., 2017).

Townsend (2013) discusses the relationship between innovation, change, and the public sector. Leadership in the organization plays an essential role in determining various ways of resolving the dynamics of change and innovation. According to Gelard, Mirsalehi, and Saleh (2010), transformational leadership is more receptive to change and encourages innovation. The purpose of doing innovation in an organization is to make the organization innovative, but this innovation step is closely related to cultural change in public sector organizations. (Yasir, Imran, Irshad, Mohamad, and Khan, 2016).

Change management is related to organizational culture, organizational culture innovation, and resistance to change. Additionally, it requires a realignment of strategic orientation and Human Resource Management within the scope of public sector organizations.

Problem formulation:

1. This study deals with the challenges in the society 5.0 era, namely technology, innovation, and culture, which are related to leadership and change to understand how disruptive innovation is implemented in public sector organizations.

2. To identify how strategic orientation and strategic human resource management practices influence organizational innovation in public organizations.

\section{Innovation and Cultural Change}

According to Volberda et al. (2012), there is a relationship between innovation and organizational culture and employees. These days, organizational change has become essential to be carried out in public management practices, but an implementation problem in various public sector organizations is rarely studied. The focus of attention is more on content than on how the change process in public organizations is implemented. In addition, there is a relationship between disruptive innovation and how the organization conducts its operations. According to Yasir, Imran, Irshad, Mohamad, and Khan (2016), organizational cul- ture plays a vital role in shaping the framework of thought and action needed by leaders of public organizations that provide social value. Various researchers express a similar view that public sector innovation requires a different government structure, such as incorporating social innovation into government social policy (Boersma, 2016; Moussa et al., 2018; Sangiorgi, 2015; McNeill, 2017). Organizational culture plays an essential role in organizational development and organizational performance (Adu Gyamfi, 2016). Within the conceptual framework of Moussa et al. (2018), innovation in the workplace is influenced by three areas, namely barriers, environmental problems, and leadership skills. In fact, the obstacle mindset can be turned into opportunities because what is considered an obstacle will not stop innovation; it is, even more, a challenge that can be overcome by innovation (Moussa et al., 2018). This condition requires the organizational environment and leadership behavior that supports creating an organizational culture of innovation in the workplace. Leadership in the organization must support and encourage innovation as a form of appreciation for employee innovation. (Moussa et al., 2018).

Innovations carried out by the public sector will be different from innovations in the private sector (Boukamel et al., 2017). The differentiating factor is the political landscape and the handling of changes to societal demands or needs as the public sector deals with more complex issues. This will require the public sector to develop more complex innovative solutions that may require more excellent resources (Sahni, Maxwell, and Christensen, 2013). Innovative breakthroughs occur in the public sector because it has undergone significant transformations to overcome the social, economic, and political structures that develop from post-industrial societies (Iacovino, Barsanti, \& Cinquini, 2017).

\section{Change Management}

Transformation in the organization will not be separated from the vital role of change management (Yasir, Imran, Irshad, Mohamad, and 
Khan, 2016). The ability of an organization to adapt to circumstances and be innovative is reflected in the organization's ability to deal with various changes (Benerjee, 2016). In the information age, organizations must share changes to run a business following the changing times. It has been proven that the successful implementation of business operations and the concept of information technology is more determined by change management (Sutanto et al., 2008).

This also applies to public organizations because technological pressures and demands from regulators to provide good services to the community encourage change in public organizations (Sutanto et al., 2008).

All organizations, including the public sector, cannot avoid changes. In fact, the changes that occur can become challenges to innovate. The failure of public organizations to adopt new technology will undoubtedly hamper their ability to provide excellent service to the communities they serve. (Townsend, 2013).

Jones et al. (2016) state a relationship between organizational change and leadership in public organizations. Change is a top-down activity that was planned from before. Topdown communication is part of planning because this communication is done as a medium to see and inform the changes (Jones et al., 2016). According to Sang, Taewon, and Donghyun (2012), managers usually socialize these changes in the organization, but as explained earlier, innovation is a process that starts from the bottom-up. Current environmental dynamics, forcing companies to change and adjust to maintain their status to achieve organizational goals (Andalibi et al., 2013).

The implementation of information technology systems is often seen as an agent of significant organizational change (Gouker, 2009). An essential part of successful innovation involves change management because, without it, the application of new technology becomes a challenge. It is recognized that change management is necessary to successfully implement information technology (Sutanto, Kankanhalli, Tay, Raman, and Tan, 2008). Like any other organizational change, changes in support of information technology should be aimed at the staff level and the strategic level.

Change management is related to the human factor because innovative and agile workplaces replace the stable pre-information bureaucracy era, change management becomes an essential part of every introduction of new technology (Jones et al., 2016). The attitude of society towards technology is essential and it becomes a question whether this attitude of society hinders the application of innovative technology. Therefore, the introduction of new technologies and change management are inseparable across all varieties (Spacey et al., 2003).

Currently, the challenge to change for the public sector is getting stronger, especially in managing the service system to the community. These changes can be successful if it involves taking organizational culture changes in the public sector seriously (Ghiorghita \& Grzegorczyk, 2017). Changes are made throughout the organization, such as leadership, organizational culture, and all elements of employees and staff ranks. Public sector organizations have different characteristics from the private sector because the public sector must be more transparent and accountable, so this makes the public sector more careful in responding to changes (Ott \& Dickie, 2001). In the society 5.0 era, public sector organizations cannot be separated from digital innovation in their operations (Ott \& Dickie, 2001). Excellent human resources are needed to innovate, including experience, competencies, intellectual skills, and interpersonal communication skills among employees and organizational leaders (Ghiorghita \& Grzegorczyk, 2017).

Transformational leadership must carry out a strategic vision for employees and prepare the resources needed to achieve organizational goals (Ghiorghita \& Grzegorczyk, 2017). Employees are encouraged to go beyond the aspirations of personal interests to change themselves and the organization through employee participation, which will result in common organizational goals (Gotsis \& Grimani, 2016). 


\section{DISCUSSIONS}

The definition of disruptive innovation needs to be studied more inclusively. Disruptive innovation is usually referred to as marketplace and is customer-driven. According to Eggers (2012), public organizations have the strong purchasing power to encourage disruptive innovation. Some of the factors driving disruptive innovation are technology and leadership. The more leaders understand innovative technologies, the more likely the organizational changes to occur. The technical and cultural challenges for public sector organizations may lead to opportunities for growth and development. Adaptability and agility play an essential role in dealing with the challenges of technology and cultural change. There is a reciprocal relationship between adaptability, agility, and organizational culture to how the organization overcomes various existing problems. As an understanding of what disruptive innovation means for public organizations, namely how public organizations apply the concept. When the public sector applies this concept, disruptive innovation driven by technology will create change. Some organizations see this paradigm shift and as a way for organizations to carry out organizational and cultural reforms.

According to the author, there are several important things on how disruptive innovation is applied in public sector organizations, namely:

1. Applying change management to innovation. Culture has a strategic role in adopting innovations in an organization, and the successful adoption of innovative ideas or processes depends on the inclusion of change management. Therefore, the organization can move forward and adapt to changes to the environment that adjusts to the interests of society. If the change process has resistance to changes that have an impact on the adoption of innovation, then the role of change management becomes the driving force for the entire organization in preparing for transformation and adaptation to these changes.

2. Public sector organizations need to create a disruptive innovation model. This is because public sector organizations do not have a market like private sector organizations but have external and internal forces that influence the way they work, so disruptive innovation is defined as creating a model that must force fundamental changes to be creative and adaptive.

3. Technology support. Technology has been the driving force for many innovative changes in organizations. Technology is the driving force that supports change and reform, and innovation (Romanelli, 2017). However, if it is only related to technology, it will not create innovation, as it requires an organizational culture change and how organizational culture is developed to adapt to the introduction of new technologies.

Introducing technology to the public sectors helps these organizations make internal corrections to become knowledge-oriented organizations based on information technology (Romanelli, 2017). The introduction of technology in organizations opens doors in modernization by managing information and knowledge, making organizations implement disruptive innovations in their organizational culture (Shibambu and Ditsa, 2017).

Furthermore, to identify the strategic orientation and practice of Strategic Human Resource Management in public organizations, it is necessary first to understand that the leadership of public organizations certainly faces environmental uncertainty. This requires options and approaches to respond effectively to challenges of public organizations that can be identified as follows:

1. Public sector organizations need knowledge of environmental uncertainty in the public sector. Public sector organizations need to respond to demands and pressures on economic, social, and environmental challenges. The public sector innovation environment can be in the form of smaller budgets, public expectations of easy and flexible access to services, and global problems that face today's society.

2. Public organizations need to know the unique strategic orientation of a public sector organization, for example, social value orientation/public value orientation, citizen orientation, collaborative governance orientation, to 
provide a more practical approach to innovation in the specific public sector desired, knowledge about orientation/ non-profit practices in the public sector, for example, strategic orientation, customer orientation, market orientation, technology orientation, and strategic human resource management practices. However, public sector organizations' leaders need to choose more deftly when to adopt a profit orientation and the unique orientation of public organizations. Without this knowledge, the organizations may experience ineffective results because leaders of public sector organizations, in initiating organizational innovation, need to adapt and accommodate profitoriented innovation practices.

Public sector organizations' leaders can expect more positive results with a cultural approach, if in a public sector organization they understand the uncertainties of the cultural environment they face using the knowledge of the strategic orientation of public organizations, such as resource orientation, custodian orientation/mission orientation, collaborative orientation/relational orientation, reputation orientation, orientation to the expert selection system, and orientation to the peer selection system.

In addition, it is also for knowledge about orientation/primary/supporting practices that are suitable for public organizations, such as: service orientation, quality orientation, market orientation, technology orientation, learning orientation, and strategic human resource management practices. This knowledge will ensure that the leadership of public organizations is well equipped with the analytical framework and the set of primary and supporting orientations/practices.

3. Public organizations have restrictive processes that need to be mitigated before organizational innovation can grow. Two things are needed in strategic orientation and human resource management to overcome contingency factors, namely:

a. The understanding that inhibiting processes can be perceived as environmental and task uncertainties.

b. Affecting environmental uncertainty requires direct alignment with the contingency factors of strategic orientation or strategic human resource management practices.

4. Development of an innovative framework. Using an organizing framework, organizational leaders can group what would be different and unrelated orientations/practices into a cohesive whole package and stack. This will generate a clearer strategic rationale of organizational innovation, thus help in articulating strategic plans and communications.

\section{CONCLUSION}

Contingency theory and institutional theory provide a critical perspective in the assessment of what contributes to innovation outcomes. An organization possesses a unique set of responses to environmental uncertainty to develop an innovation strategy that combines a strategic orientation and strategic human resource management practices. Some important things related to the innovation strategies of public sector organizations in strategic orientation and Human Resource Management include:

1. Understanding how public sector organizations can identify environmental orientation and uncertainty.

2. To develop a clear perspective, it is necessary to identify appropriate options for selecting innovation strategies for public sector organizations.

3. Correctly align external uncertainty with the orientation faced externally and align the uncertainty faced internally with the orientation faced internally.

4. Value built with an analytical framework in the management of public organizations emphasizes a more nuanced perspective across sectors and accommodates unique perspectives.

\section{REFERENCES}

Agolla, J.E., \& Van Lill, J.B. 2017. A Structural Equation Modeling of Innovation in Public Sector Organizations. African Journal of Business and Economic Research, 12(1): 107-140. 
Andalibi, M.A., Rafizadeh, K., Salimi, B., \& Khleghi, M.R. 2013. Effects of technology and change management on the business. Interdisciplinary Journal of Contemporary Research in Business, 5(2): 618625.

Boersma, R. 2016. Public sector or private sector, innovation is innovation. Municipal World, 126(11): 13.

Boukamel, O., \& Emery, Y. 2017. Evolution of organizational ambidexterity in the public sector and current challenges of innovation capabilities. The Innovation Journal, 22(2): 1-27.

Demircioglu, M.A. 2017. Three Essays on Public Sector Innovation. (10276549 Ph.D.), Indiana University, Ann Arbor. Retrieved from ProQuest Dissertations \& Theses Global database.

Eggers, W., Baker, L., Gonzalez, R., \& Vaughn, A. 2012. Disruptive innovation: a new model for public sector services, Strategy \& Leadership. Vol. 40(3): 17-24.

Gelard, P., Mirsalehi, S.P., \& Saleh, K.E. 2010. The Relationship Between Strategic Leadership and Innovation [European Conference on Innovation and Entrepreneurship], Reading: 238XIII. Reading: Academic Conferences International Limited. (Sep 2010).

Ghiorghita, E., \& Grzegorczyk, A. 2017. Knowledge Management as a Strategic Business Resource. Journal of Economic Development, Environment and People, 6(2): 63-72.

Gotsis, G., \& Grimani, K. 2016. Diversity as an aspect of effective leadership: integrating and moving forward. Leadership \& Organization Development Journal, 37(2): 241-264.

Gouker, T.R. 2009. Information technology-enabled change management: An investigation of Individual experiences. Walden University. Retrieved from ProQuest Dissertations and Theses.

Iacovino, N., Barsanti, S., \& Cinquini, L. 2017. Public Organizations Between Old Public Administration, New Public Management and Public Governance: The Case of the Tuscany Region. Public Organization Review, 17(1): 61-82.

Jones, S.L., \& Van de Ven, A.H. 2016. The Changing Nature of Change Resistance: An Examination of the Moderating Impact of Time. The Journal of Applied Behavioral Science, 52(4): 482-506.

McNeill, J. 2017. Enabling social innovation assemblages: Strengthening public sector involvement. (10633311 Ph.D.), Western Sydney University (Australia), Ann Arbor. Retrieved from ProQuest Dissertations \& Theses Global database.

Moussa, M., McMurray, A., \& Muenjohn, N. 2018. A Conceptual Framework of the Factors Influencing Innovation in Public Sector Organizations. The Journal of Developing Areas, 52(3): 231-240.

Ott, J.S., \& Dicke, L.A. 2001. Challenges facing public sector management in an era of downsizing, devolution, dispersion and empowerment - and account- ability? Public Organization Review, 1(3): 321. Retrieved from Proquest.com

Romanelli, M. 2017. Rethinking Public Organizations as Knowledge-Oriented and Technology-Driven Organizations. Management Dynamics in the Knowledge Economy, 5: 559-576.

Sahni, N.R., Wessel, M. \& Christensen, C. 2013. Unleashing Breakthrough Innovation in Government. Stanford Social Innovation Review. Retrieved from https://ssir.org/articles/entry/unleashing breakthrou gh innovation in government

Sang, M.L., Taewon, H., \& Donghyun, C. 2012. Open Innovation in the Public Sector of Leading Countries. Management Decision, 50(1): 147-162. doi: 10.1108 / 00251741211194921

Sangiorgi, D. 2015. Designing for public sector innovation in the UK: design strategies for paradigm shifts. Foresight: The Journal of Futures Studies, Strategic Thinking and Policy, 17(4): 332-348.

Shibambu, A., \& Ditsa, G. 2017. Analysis of Information Technology Infrastructure Towards Improving Services in the Public Sector. Journal of Information Technology and Economic Development, 8 (1): 33-44.

Spacey, R., Goulding, A., \& Murray, I. 2003. ICT and change in UK public libraries: Does Training Matter?. Library Management, 24(1): 61-69. Retrieved from Proquest.com

Sutanto, J., Kankanhalli, A., Tay, J., Raman, K.S., \& Tan, B.Y 2008. Change Management in Interorganizational Systems for the Public. Journal of Management Information Systems, 25 (3): 133-175.

Townsend, W. 2013. Innovation and The Perception of Risk in the Public Sector. International Journal of Organizational Innovation (Online), 5(3): 21-34. Retrieved from Proquest.com

Volberda, H.W., Van Der Weerdt, N., Verwaal, E., Stienstra, M., \& Verdu, A.J. 2012. Contingency fit, institutional fit, and firm performance: A metaphorical approach to organization - environment relationships. Organization Science, 23(4): 1040-1054.

Yasir, Imran, Irshad, Mohamad, \& Khan. 2016. Leadership Styles in Relation to Employees Trust and Organizational Change Capacity: Evidence from Non-Profit Organizations. SAGE Open, 6 (4): 1-12. 